\title{
TOMADA DE DECISÃO DO ENFERMEIRO FRENTE AOS CONFLITOS E DILEMAS ÉTICOS VIVENCIADOS NA VIOLÊNCIA OBSTÉTRICA NO CONTEXTO HOSPITALAR
}

\author{
Analu Sousa de Oliveira $^{1}$; Elaine Guedes Fontoura ${ }^{2}$ \\ 1. Bolsista FAPESB, Graduanda em Enfermagem, Universidade Estadual de Feira de Santana, e-mail: \\ analulubarbosa@hotmail.com \\ 2. Orientadora, Departamento DSAU, Universidade Estadual de Feira de Santana, e-mail: elaineguedesfont@uol.com.br
}

PALAVRAS-CHAVE: Ética; Enfermeiros; Tomada de decisão; Centro Obstétrico.

\section{INTRODUÇÃO}

A violência obstétrica proporciona de maneira indireta ou direta à apropriação inadequada dos processos corporais e reprodutivos das mulheres. Expressa-se em tratamento desumano, abuso da patologização dos processos fisiológicos, além do uso inadequado e desnecessário da tecnologia científica, o que reflete na perda de autonomia da parturiente, diante do desrespeito aos seus diretos, impactando de maneira negativa na sua qualidade de vida (SAUAIA; SERRA, 2016).

Na prática hospitalar o enfermeiro costuma se deparar com situações de negligência, como a violência obstétrica, propiciando o surgimento de conflitos e dilemas éticos, que quando não são resolvidos, corroboram para o surgimento do sofrimento moral, situação caracterizada, pela incapacidade de realizar a ação correta a ser seguida, devido a razões e circunstâncias que ultrapassam a sua competência (DALMOLIN et al., 2014).

Para que ocorra uma tomada de decisão, é preciso que haja reflexão, ponderação e discussão, tendo como base o conhecimento científico, os princípios éticos e a deontologia (normas ou regras de conduta agregadas).

Portanto, é de suma importância que as decisões tomadas pelo enfermeiro frente à violência obstétrica, reflitam em um cuidado intersubjetivo e integral no que tange os cuidados obstétricos, de acordo com o seu dever profissional e ético.

Enquanto bolsista do Núcleo Interdisciplinar de Pesquisa e Estudos em Saúde (NIPES), percebi a atual relevância do tema violência obstétrica, decorrente da falta de ética, valores morais e problemas de relacionamento, culminando em conflitos e dilemas. Essa situação abrange os enfermeiros obstetras, que tem como uma de suas funções o cuidado e a assistência integral a mulher gestante, antes durante e após o trabalho de parto. Diante do exposto, emergiu a pergunta de investigação: Como o enfermeiro toma decisão frente aos conflitos e dilemas éticos vivenciados na violência obstétrica?

\section{METODOLOGIA}

Para compreensão dos conflitos e dilemas éticos vivenciados pelos enfermeiros frente à tomada de decisão na situação de violência obstétrica, foi realizada uma pesquisa qualitativa descritiva, por trabalhar com um universo de significados e oferecer a oportunidade do pesquisador de entender e explorar as questões relacionadas a pessoa e sua prática. $\mathrm{O}$ estudo foi desenvolvido no Centro Obstétrico (CO), com cinco enfermeiras de um hospital especializado, público, situado no município de Feira de Santana-BA. A coleta de dados com os enfermeiros da unidade de CO aconteceu entre novembro de 2019 e janeiro de 2020 por meio de uma entrevista semiestruturada, gravada. Foram utilizados os seguintes critérios de inclusão: ser enfermeiro do $\mathrm{CO}$, estar trabalhando na assistência a mulher em processo parturitivo no $\mathrm{CO}$; estar em atividade no $\mathrm{CO}$ há no mínimo por três meses. O primeiro contato foi com a enfermeira Coordenadora do setor de $\mathrm{CO}$, que possibilitou o acesso aos enfermeiros. A autonomia dos participantes e declaração de interesse em participar do estudo foram mantidas. Após conhecimento das informações fornecidas, leitura e compreensão das 
informações constantes no Termo de Consentimento Livre e Esclarecido (TCLE) que foi assinado para a realização da entrevista. As entrevistas foram realizadas em um local reservado e livre de interrupções, onde as participantes se sentiam confortáveis. As mesmas foram agendadas individualmente, conforme a disponibilidade dos enfermeiros do $\mathrm{CO}$ que desejaram participar. Cada entrevista teve uma duração de aproximadamente 10 minutos. Teve como questão norteadora: Comente a sua compreensão sobre conflito e dilema ético relacionado com a violência obstétrica? E questões de aproximação: Fale-me sobre uma situação de acompanhamento da mulher em situação de violência obstétrica, e sua tomada de decisão? Comente sobre que estratégias utiliza para proporcionar cuidados à mulher em situação de violência obstétrica? As entrevistas foram transcritas na íntegra. A confidencialidade e o anonimato foram assegurados mediante uso de pseudônimos (enfermeiro 1; enfermeiro 2; enfermeiro 3; enfermeiro 4; enfermeiro 5) conforme a ordem em que aconteceu a entrevista. Para a concretização do processo de análise foi utilizado análise de conteúdo de Bardin como modo de revelar a síntese da estrutura das categorias empíricas. A análise de conteúdo é um "conjunto de técnicas de análise das comunicações" (BARDIN, 2016, p. 37). Para o autor, será um único instrumento, marcado com uma grande disparidade de formas e adaptável a um vasto campo de aplicação.

\section{RESULTADOS E DISCUSSÃO}

As entrevistas foram realizadas com 05 enfermeiras que atuam no $\mathrm{CO}$ de um Hospital da Mulher na cidade de Feira de Santana, com no mínimo três meses de experiência. A idade das entrevistadas variou entre 27 a 38 anos, dentre elas a profissional com maior tempo de formação tem nove anos de formada e a com menor tempo tem três anos. Todas são especialistas em obstetrícia, duas delas não possuem outro vínculo empregatício. A percepção das profissionais acerca dos conflitos e dilemas éticos em situações de violência obstétrica revelada nos discursos de diferentes formas, encontram-se organizadas em cinco categorias e 10 subcategorias. Categoria 1 - Situações de violência obstétrica: O profissional de enfermagem exerce um importante papel durante os períodos de pré-parto, parto e pós-parto, proporcionado à parturiente uma assistência humanizada. Em situações de violência obstétrica, é comum que a paciente se sinta com medo e insegura. Portanto, cabe a equipe de enfermagem, oferecer suporte psicológico a mulher, através de uma escuta qualificada, sem julgamentos, possibilitando que ela compartilhe suas emoções, e a criação de um elo entre enfermeira e paciente. E a partir daí, prestar as orientações necessárias (OLIVEIRA; SILVA, 2019). Subcategoria I - Realização de intervenções desnecessárias durante o trabalho de parto: Os relatos demonstram que as profissionais de enfermagem não concordam com a realização de procedimentos invasivos no momento do parto, a exemplo da manobra de Kristeller, que mesmo sendo uma prática desaconselhada no ambiente hospitalar ainda ocorre com frequência, com a finalidade de acelerar a expulsão do bebê durante o parto. Constitui-se como um método que desrespeita a integridade física da parturiente, expondo a mãe e o recém-nascido a riscos de complicações a saúde, como lesões nos órgãos internos, hematomas, fraturas, entre outros, além de gerar violência psicológica à gestante (LEAL et al., 2018; SAUAIA, SERRA, 2016). Subcategoria II - Falta de informação da parturiente: Em seus relatos as enfermeiras obstetras retratam que muitas pacientes não conseguem reconhecer situações de violência obstétrica, devido à ausência de informação. Portanto, compreendem que todos os procedimentos os quais estão sendo submetidas, irão ajudar a salvar a vida dela e a do bebê, tendo a figura do médico como um herói (LEAL et al., 2018). Sendo a falta de informação, por parte da paciente o fator que une todos os tipos de violência obstétrica, visto que contribui para a perda da autonomia feminina no momento do parto (ALVARENGA; KALIL, 2016). Categoria 2 - Estratégias de cuidado à mulher em situação de violência: $O$ processo de cuidar é imprescindível no trabalho da equipe de 
enfermagem. Cabe a enfermeira obstetra ao se deparar com uma mulher em situação de violência obstétrica, desenvolver estratégias para prestar os cuidados necessários as suas necessidades sociais, psicológicas, físicas e emocionais, saber ouvi-las e orienta-las, estabelecendo uma relação de troca, que favorece a confiança entre profissional e paciente (SILVA et al., 2016). Subcategoria I - Assistência e orientação à parturiente: Em suas falas, as enfermeiras destacaram a orientação como ação essencial da sua assistência a mulher em situação de violência obstétrica, além de informa-la sobre o ocorrido e incentivá-la a buscar os seus direitos no âmbito da justiça, citando não só a ouvidoria do hospital, mas também a defensoria pública. Portanto, a informação e a orientação adequadas fazem parte de uma assistência com funções qualificadas e educativas, permitindo que a partir do conhecimento a mulher se empodere e seja capaz de tomar as rédeas da situação (LEAL, et al., 2018; ALVARENGA, KALIL, 2016). Subcategoria II - Divergência com a equipe médica: Segundo depoimentos das enfermeiras alguns médicos não concordam com a prática do parto humanizado, comportamentos como esses são comuns no $\mathrm{CO}$, e geram a fragmentação do cuidado, impossibilitam uma assistência de qualidade e propiciam o surgimento de conflitos e dilemas éticos, onde a equipe de enfermagem diverge com a equipe médica, mas optam por manter a assistência a parturiente. Logo, percebe-se que o discurso biomédico hegemônico, foca seus argumentos na noção de risco do parto vaginal, onde justifica o excesso de procedimentos como imprescindíveis à boa prática obstétrica, em que a capacidade de escolha sobre o parto passar a ser exclusividade médica. E o enfermeiro obstetra, por possuir uma formação que visa uma assistência humanizada, e que respeita a fisiologia do parto, apesar de discordar da postura médica, continua assistindo a paciente (PALHARINI, 2017; SILVA, et al., 2015). Categoria 3 - Conflito Ético: O conflito pode ser compreendido "como a quebra da ordem, uma experiência negativa, gerada por erro ou falha" (AMESTOY, et al., p.80, 2014). Percebe-se que o conflito no CO surge na rotina das relações interdisciplinares entre a equipe de saúde, e costuma estar relacionado a diferentes opiniões sobre ações realizadas durante o parto, principalmente entre a equipe médica e equipe de enfermagem. Subcategoria I - Compreensão sobre o conflito: Ao abordarem a compreensão sobre o conflito, as enfermeiras se expressaram de forma equivocada em determinados momentos. Elas vivenciam conflitos por estarem frente a diferentes possibilidades e pelo ambiente do $\mathrm{CO}$ ser dinâmico que atende a procedimentos complexos exigindo dos mesmos escolhas rápidas, a fim de evitar danos a paciente e ao bebê. Subcategoria II - Conflitos entre a equipe multiprofissional: O trabalho na área da saúde é complexo, por isso é comum o aparecimento de conflitos entre as diversas categorias profissionais. Entrar em conflito é algo inerente ao ser humano, visto que cada indivíduo possui suas concepções, crenças, atitudes, senso de ética, moral, costumes, etc. É comum que ocorra a divergência de opiniões, e muitas vezes, a situação conflituosa foi necessária para a construção de novos conceitos (LEAL et al., 2018). As enfermeiras retratam em suas falas a discordância entre os profissionais da equipe surge esporadicamente, e a maneira como a equipe de saúde do CO costuma resolver as situações conflituosas, através de uma tentativa de negociar em conjunto com todos os profissionais envolvidos. Ressaltando que a resolução dos conflitos influencia positivamente a organização do trabalho e favorece a construção de objetivos comuns, intensificando a articulação entre os profissionais e a atuação da equipe multiprofissional (SANTOS et al., 2016). Categoria 4 - Dilema Ético: Os dilemas ocorrem quando emerge uma situação em que há duas opções de escolha, e ambas ferem os princípios éticos. No dilema ético o profissional de enfermagem vivencia uma situação limite, a qual impõe o desafio de ser obrigado a escolher entre dois, e somente dois, incompatíveis cursos de ação (OLIVEIRA, SANTA ROSA, 2015; NORA et al., 2015). Subcategoria I Conhecimento sobre dilema: Observa-se que as enfermeiras já vivenciaram situações de dilemas éticos $\mathrm{e}$ as mesmas têm diferentes concepções sobre o seu significado. $\mathrm{O}$ 
reconhecimento de um dilema, configura-se como um passo importante na construção de profissionais éticos, visto que por diversas vezes situações dilemáticas passam despercebidas ou são confundidas com conflitos. Assim sendo, apesar de demonstrarem compreensão sobre o conceito do dilema, as enfermeiras do $\mathrm{CO}$ devem aprimorar o seu discernimento, para que se sintam mais seguras na identificação e na resolução de um dilema (OLIVEIRA; SANTA ROSA, 2016). Subcategoria II - Ação da enfermeira diante de um dilema: Em sua fala a enfermeira E3 revela nunca ter vivenciado uma situação conflituosa ou dilemática, mas afirma que se estivesse inserida numa situação de dilema ético, tentaria resolver da maneira mais correta possível, ou seja pautada nos princípios éticos que permeiam a profissão. Pois, a resolução dos dilemas que permeiam o cotidiano da profissão perpassa pela identificação do mesmo, e por uma análise ética, onde faz- se importante um posicionamento de forma crítica e reflexiva para que a tomada de decisão seja subsidiada por princípios e valores éticos (SILVA, et al., 2018). Categoria 5 - Tomada de Decisão: Como já foi dito, em seu cotidiano o profissional de enfermagem do $\mathrm{CO}$ defronta-se com inúmeras situações de conflitos e dilemas, e é constantemente confrontado com necessidade de uma tomada de decisão ética. A tomada de decisão decorre da escolha, entre duas ou mais alternativas, a fim de que se chegue a um resultado. Sendo, portanto, imprescindível diante de um dilema ético (NORA et al., 2015; OLIVEIRA; SANTA ROSA, 2015). Subcategoria I - Relação com a equipe multiprofissional: Segundo as falas das enfermeiras, a tomada de decisão deve ser realizada em conjunto com a equipe de obstetrícia do hospital, pois quanto mais perspectivas e opiniões forem discutidas, maior a probabilidade que a decisão ética seja prudente e correta. Além disso o diálogo com a equipe torna-se capaz de minimizar situações de conflito ético (NORA, et al., 2015). Subcategoria II - Autonomia da enfermeira: As enfermeiras compreendem o significado da autonomia no âmbito profissional, e buscam colocá-la em prática no seu cotidiano, através de ações como: conduzir a assistência, resolver conflitos, e buscar o melhor resultado possível durante a sua assistência. Para que ações como essas sejam viáveis, além da autonomia, é necessário o aprendizado teórico e prático, pois não há como ser autônomo sem ter o conhecimento.

\section{CONSIDERAÇÕES FINAIS}

Este estudo possibilitou conhecer a tomada de decisão da enfermeira frente aos conflitos e dilemas éticos vivenciados em situação de violência obstétrica em um hospital da mulher da cidade de Feira de Santana, Bahia. De acordo com o que foi analisado, a compreensão das enfermeiras quanto ao significado da palavra conflito foi equivocada. Apenas uma profissional soube informar o significado da palavra, o que revela a necessidade de um conhecimento teórico mais amplo. Quanto ao significado da palavra dilema as enfermeiras desvelaram uma maior compreensão, apesar de não haver nenhum relato sobre a vivência do mesmo durante a prática hospitalar. Conclui- se que a resolução das situações conflituosas e dilemáticas está fundamentada não só no conhecimento teórico, mas também na autonomia da enfermeira e na sua capacidade de tomar decisões. Decisões essas que no CO costumam ser tomadas em comum acordo com a equipe multiprofissional, visando a qualidade do serviço prestado e o bem estar da paciente. As limitações do estudo ocorreram devido a sua realização em uma única instituição de saúde, e por constar na literatura científica poucos estudos relacionados ao mesmo.

Contudo, como contribuição, este estudo propôs estratégias de ação diante da violência obstétrica, pautadas nos princípios éticos e bioéticos. Incentivando a escolha de posturas éticas e no desenvolvimento de habilidades para a tomada de decisão.

\section{REFERÊNCIAS}


ALVARENGA, S. P.; KALIL, J. H. Violência obstétrica: como mito "parirás com dor" afeta a mulher brasileira. Revista da Universidade Vale do Rio Verde, Três Corações, v. 14, n. 2, p. 641-49, 2016.

AMESTOY, S. C., et al. Gerenciamento de conflitos: desafios vivenciados pelos enfermeiros-líderes no ambiente hospitalar. Revista Gaúcha de Enfermagem, v.35, n.2, p.79-85, 2014.

BARDIN, Laurence. Análise de conteúdo. São Paulo: Edições 70, 279 p. 2016.

DALMOLIN, G. L. Enfermeiros, técnicos e auxiliares de enfermagem: quem vivência maior sofrimento moral?. Revista da Escola de Enfermagem da USP, São Paulo, v.48, n.3, p.521529, abr. 2014.

LEAL, S. Y. P. et al. Percepção de Enfermeiras Obstétricas Acerca da Violência Obstétrica. Revista Cogitare Enfermagem, Paraná, v. 23, n. 2, 2018.

NORA, C. R. D. et al. Elementos e estratégias para a tomada de decisão ética em enfermagem. Revista Texto e Contexto Enfermagem, Santa Catarina, v. 25, n. 2, p. 1-9, set. 2015.

OLIVEIRA, F. S.; SILVA, F. A. Violência obstétrica- características no cotidiano da enfermagem obstétrica: revisão bibliográfica. 2019. 21f. Dissertação (bacharelado em enfermagem) - Centro Universitário São Lucas, Porto Velho, 2019.

OLIVEIRA, M. A. N.; SANTA ROSA, D. O. Conflitos e dilemas éticos vivenciados pelo enfermeiro no cuidado perioperatório. Ciência, Cuidado e Saúde, v. 14, n. 2, p. 1149-1156, 2015.

OLIVEIRA, M. A. N.; SANTA ROSA, D. O. Conflitos e dilemas éticos: vivências de enfermeiras no centro cirúrgico. Revista Baiana de Enfermagem. Salvador. v. 30, n. 1, p. 344-355, 2016.

PALHARINI, L. A. Autonomia para quem? O discurso médico hegemônico sobre a violência obstétrica no Brasil. Cadernos Pagu, Campinas, v. 49, 2017.

SANTOS, F. A. P. S. Autonomia do enfermeiro obstetra na assistência ao parto de risco de habitual. 2016. 150f. Dissertação (doutorado em enfermagem) - Centro de Ciências da Saúde, Universidade Federal do Rio Grande do Norte, Natal, 2016.

SAUAIA, A. S. S.; SERRA, M. C. M. Uma dor além do parto: violência obstétrica em foco. Revista de Direitos Humanos e Efetividade, Brasília, v.2, n.1, p.128-147, jan/jun. 2016.

SILVA, A. A. et al. Violência obstétrica: perspectiva da enfermagem. Revista Rede de Cuidados em Saúde, v. 32, n. 3, p. 479-86, 2015.

SILVA, A. C. O. C. et. al. Dilemas éticos vivenciados na prática dos enfermeiros no centro cirúrgico. In: V CONGRESSO ONLINE - GESTÃO, EDUCAÇÃO E PROMOÇÃO DA SAÚDE, 2016, São Paulo. Anais eletrônicos. São Paulo: CONVIBRA, 2016.

Silva T. N., et al. Vivência deontológica da enfermagem: desvelando o código de ética profissional. Revista Brasileira de Enfermagem, v. 71, n.1, p. 7-15, 2018. 
